\title{
COMPARISON OF MORPHOLOGY OF CORROSION PRODUCTS OF HIGH-TEMPERATURE ALLOY ON THE FEAI INTERMETALLIC PHASE MATRIX
}

\author{
Dorota PASEK, Janusz CEBULSKI, Maria SOZAŃSKA \\ Silesian University of Technology, Katowice, Poland, EU, \\ dorota.pasek@polsı.pl, janusz.cebulski@polsl.pl, maria.sozanska@polsl.pl
}

https://doi.org/10.37904/metal.2019.921

\begin{abstract}
The alloys based on intermetallic phases involving aluminum belong to group of heat resistant materials. Their physic-chemical and mechanical properties allow to apply them in the operating conditions in corrosive environment and elevated temperature. Research conducted for many years has shown that these materials can work in temperature to $1100{ }^{\circ} \mathrm{C}$. The paper presents the morphology of oxides formed during oxidation Fe40Al5Cr0.2TiB alloy in $700{ }^{\circ} \mathrm{C}$ during 300,1000 and $2000 \mathrm{~h}$ in the air and water vapor environment. In addition, the material was after casting and after plastic processing. The study allows to define the surface condition and morphology of corrosion products carried out using scanning electron microscopy together with EDS X-ray microanalysis.
\end{abstract}

Keywords: FeAl alloys, corrosion resistance, oxidation, $\mathrm{Al}_{2} \mathrm{O}_{3}$ scale

\section{INTRODUCTION}

Fe-Al intermetallic compounds are regarded as promising materials for industrial applications because of their low cost, low density, high specific strength, high temperature strength, as well as excellent oxidation and corrosion resistance [1-3]. Aluminides enriched by iron, thanks to the $\mathrm{Al}_{2} \mathrm{O}_{3}$ layer formed on their surfaces, are resistant to high temperature oxidation and sulfurization. Recent studies showed also that alloys of iron containing $36-38$ at\% aluminum are very resistant to carbonizing at $1000{ }^{\circ} \mathrm{C}$ in the environment simulating ethylene pyrolysis and steam reforming $[4,5]$. Binary FeAl alloy has a B2 crystal structure which exists over a wide range of compositions, from about 36 at $\% \mathrm{Al}$ to 50 at $\% \mathrm{Al}$ at room temperature and maintains its $\mathrm{B} 2$ structure to its melting point [6]. These characteristics allow considerable solubility for third element additions and offer a potential of producing an acceptable material by alloying. However, different alloying elements will play different roles in the oxidation resistance of FeAl alloy. The investigations on the effect of some alloying elements, such as $\mathrm{Hf}, \mathrm{Zr}, \mathrm{Y}, \mathrm{Si}, \mathrm{B}$, on the oxidation behavior of $\mathrm{FeAl}$ alloy have been reported by some researchers [7-9]. In order to overcome problems with their low ductility, a lot of effort have been made so far in the area of their mechanical behavior at room and high temperatures, putting emphasis on the relationship between their microstructure and mechanical properties. Nowadays, hot and warm working of as-cast Fe-Al ingots by forging, rolling or extrusion in the range of $600-1100^{\circ} \mathrm{C}$, i.e. in the B2-A2 structure regime, is used to produce rod, wire, sheet and tube products [10-12]. In the paper, the results of the tests on the comparison of the oxidation resistance of Fe40AI5Cr0.2TiB alloy in the state after casting and after plastic processing were presented. The oxidation process was carried out in the environment of air and water vapor.

\section{RESEARCH MATERIAL AND METHODOLOGY}

The test material was an alloy based on Fe40Al5Cr0.2TiB intermetallic phase after casting and after plastic processing by extrusion. The chemical composition of the material is shown in Table 1 . The smelting process was carried out in a vacuum, followed by homogenization annealing at $1050^{\circ} \mathrm{C}$ for $72 \mathrm{~h}$. The processed refined alloy was obtained by extrusion using technology that is patent protected [13]. From the test alloy, samples 
were made by means of spark erosion cutting in cylindrical shape. The diameter of the samples was $6 \mathrm{~mm}$ and their height was $2 \mathrm{~mm}$. Samples before oxidation were ground on 600 grit abrasive paper and degreased in acetone. The samples were then subjected to an oxidation process in the air and steam environment during 300,1000 and $2000 \mathrm{~h}$ in the post-cast condition and after plastic working. The oxidation process was carried out at $700^{\circ} \mathrm{C}$. Observations of the material surface condition after the oxidation process were carried out using the Hitachi S-3400 scanning electron microscope. The X-ray chemical composition (EDS) microanalysis of corrosion products and the base material was carried out. Before the oxidation of samples, their weight was measured on the WAW 100 / C / 1 scale by RADWAG. Samples for testing were oxidized in the ceramic cups with $\mathrm{Al}_{2} \mathrm{O}_{3}$ and placed in an oven in air and steam environment at atmospheric pressure at $700{ }^{\circ} \mathrm{C}$. Then after the set time $(300,1000$ and $2000 \mathrm{~h})$, the samples were re-weighed to determine their weight change.

Table 1 Chemical composition alloy Fe40Al5Cr0.2TiB

\begin{tabular}{|c|c|c|c|c|c|}
\hline Fe40Al5Cr0.2TiB & $\mathrm{Al}$ & $\mathrm{Cr}$ & $\mathrm{Ti}$ & $\mathrm{B}$ & $\mathrm{Fe}$ \\
\hline$(\mathrm{wt} \%)$ & 23.66 & 5.77 & 0.15 & 0.015 & rest \\
\hline
\end{tabular}

\section{EXPERIMENTAL RESULTS}

The paper specifies the change in the mass of oxidation samples, and the results of measurements are presented in Tables 2 and 3. An attempt was made to determine the corrosion kinetics of the material however due to the too large spread of results and a small number of measurements (three), the determination of the course of the oxidation process is not representative. From the information contained in the literature, it appears that the oxidation of the Fe40Al alloy in the air environment is parabolic, whereas for the environment of water vapor this relationship has not been determined so far. Tests of oxidation of the alloy on the FeAl intermetallic phase lead to the conclusion that the material after heat resistance test is covered by a heterogeneous (discontinuous) layer in both air and water vapor oxides. After oxidation at $700{ }^{\circ} \mathrm{C}$ in the air atmosphere after casting, the surface of the alloy covered with oxides was relatively small compared to the surface of the material after oxidation in the steam environment, especially after a long time of resistance in the furnace (Figures 1, 2). Scratches visible on the surface of the alloy are the result of the preparation consisting of grinding the sample before corrosion tests on the abrasive paper. In order to avoid the influence of the surface condition on the course of the oxidation process, all tested samples were prepared using the same method as the initial state of the material, and any observed surface effects of the tested alloy were changes occurring as a result of oxidation. The high aluminum content in the tested material facilitates the formation of a thin, passive layer of $\mathrm{Al}_{2} \mathrm{O}_{3}$ oxides, which form a tight, high-melting layer that prevents further corrosion of the material. Analysis of the material surface after oxidation for individual variants showed that on the plastically processed material a greater number of areas coated with corrosion products were observed. The oxidation environment had a much greater influence on the corrosion resistance of the alloy. The conducted state surface studies show that in the environment of water vapor Fe40AI5Cr0.2TiB alloy is subject to corrosion much faster than in the air environment (Table 2, 3). In addition, along with the prolongation of the oxidation time, an increase in the oxide phase was observed (Figure 2), which in the case of alloys based on the FeAl intermetallic phase is slower than in the case of corrosion products on other materials designed for high temperature operation depending on the temperature and time of the oxidation process. Figure 3 presents the results of the analysis of chemical composition in individual areas of the sample. It was found that there are areas covered with oxides on the surface and areas included in the alloy. At all three points in Figure 3, the X-ray spectrum is similar, for the examples in the paper the spectrum for point 3 is shown. In the case of Fe40AI5Cr0.2TiB alloy the water vapor oxidation process is selective. Due to the low molecular oxygen pressure of the $\mathrm{H}_{2}-\mathrm{H}_{2} \mathrm{O}$ mixture, usually only one oxide of the component of the material can be formed under these conditions. 
Table 2 Change in mass of oxidation samples (in $\mathrm{g} / \mathrm{cm}^{2}$ ) after oxidation in air environment at $700{ }^{\circ} \mathrm{C}$

\begin{tabular}{|c|c|c|c|}
\hline time & $300 \mathrm{~h}$ & $1000 \mathrm{~h}$ & $2000 \mathrm{~h}$ \\
\hline after casting & $1.12 \cdot 10^{-4}$ & $4.67 \cdot 10^{-4}$ & $5.02 \cdot 10^{-2}$ \\
\hline after plastic processing $(\mathrm{pp})$ & $1.68 \cdot 10^{-4}$ & $4.77 \cdot 10^{-4}$ & $5.75 \cdot 10^{-2}$ \\
\hline
\end{tabular}

Table 3 Change in mass of oxidation samples $\left(\mathrm{g} / \mathrm{cm}^{2}\right)$ after oxidation in water vapor environment at $700{ }^{\circ} \mathrm{C}$

\begin{tabular}{|c|c|c|c|}
\hline time & $300 \mathrm{~h}$ & $1000 \mathrm{~h}$ & $2000 \mathrm{~h}$ \\
\hline after casting & $1.28 \cdot 10^{-4}$ & $5.05 \cdot 10^{-4}$ & $1.02 \cdot 10^{-2}$ \\
\hline after plastic processing (pp) & $1.83 \cdot 10^{-4}$ & $8.84 \cdot 10^{-4}$ & $1.66 \cdot 10^{-2}$ \\
\hline
\end{tabular}

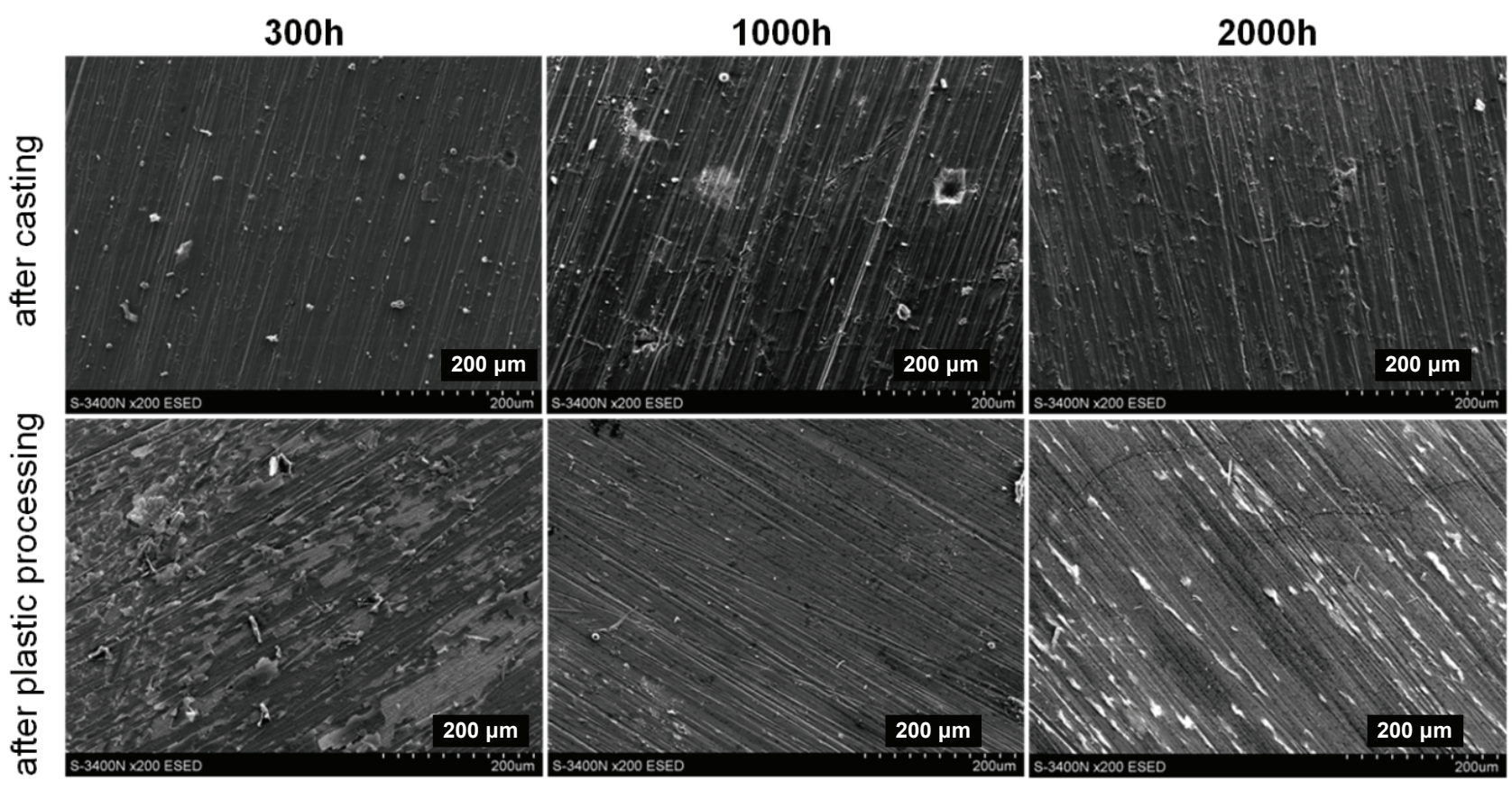

Figure 1 Surface condition of the alloy Fe40AI5Cr0.2TiB after oxidation in the air environment at $700{ }^{\circ} \mathrm{C}$ in the state after casting and after plastic processing

In the case of an alloy based on the FeAl intermetallic phase, $\mathrm{Al}_{2} \mathrm{O}_{3}$ monophase scale is formed both in the air and in the water vapor $[14,15]$. It is the only aluminum oxide that can be produced on the surface of the alloy due to the high affinity of aluminum and oxygen. The resulting passive layer usually has good protective properties, since oxides of metals showing high chemical and oxygen affinity have very little defect of the crystal lattice. Despite the presence of $\mathrm{Fe}$ and $\mathrm{Cr}$ alloys, the resulting oxides of these metals have several orders of magnitude higher corrosion rates than FeAl forming $\mathrm{Al}_{2} \mathrm{O}_{3}$ protective scale. Therefore, aluminum in Fe40Al5Cr0.2TiB alloy can oxidize selectively, forming stable $\mathrm{Al}_{2} \mathrm{O}_{3}$ oxides on the alloy surface [16].

The formation of cavities is the result of aluminum consumption and its loss in FeAl. Figure 4 shows the scale morphology of Fe40AI5Cr0.2TiB alloy plastically processed after oxidation at $700{ }^{\circ} \mathrm{C}$ for $1000 \mathrm{~h}$ in a water vapor environment. A similar morphology of the oxide layer was observed in the case of a cast alloy both in the air environment and water vapor for the remaining oxidation times. The morphology of $\mathrm{Al}_{2} \mathrm{O}_{3}$ oxides depends on the temperature of the oxidation process. In the tests carried out, they are in the form of small needles. This phenomenon results from different varieties of allotropic aluminum oxide. The determination of morphology of corrosion products for particular types of $\mathrm{Al}_{2} \mathrm{O}_{3}$ structure was made in [14]. 


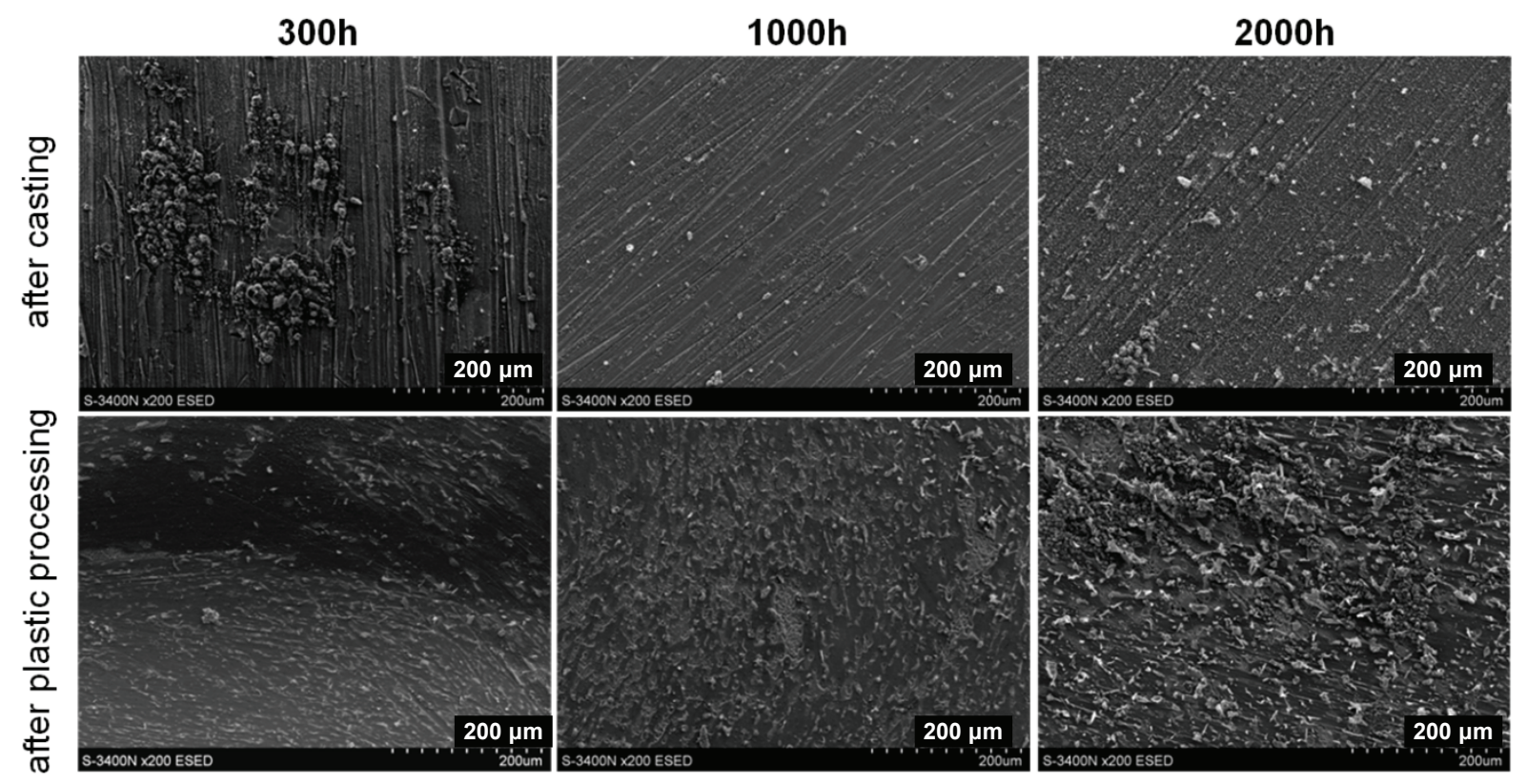

Figure 2 Surface condition of the alloy Fe40Al5Cr0.2TiB after oxidation in the water vapor environment at $700{ }^{\circ} \mathrm{C}$ in the state after casting and after plastic processing
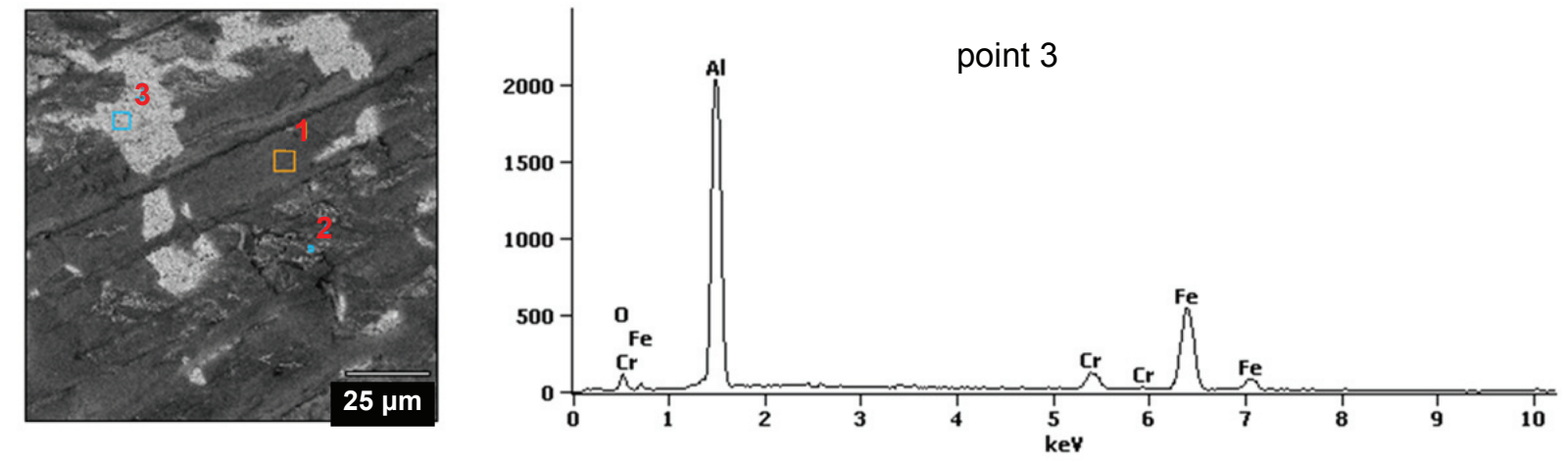

\begin{tabular}{|c|c|c|c|}
\hline Element & Al & Cr & Fe \\
\hline FeAl-pp-300h-air_pt1 & 35.1 & 6.8 & 58.1 \\
\hline FeAl-pp-300h-air_pt2 & 35.5 & 5.9 & 71.7 \\
\hline FeAl-pp-300h-air_pt3 & 21.1 & 7.2 & 7.6 \\
\hline
\end{tabular}

Figure $3 \mathrm{X}$-ray microanalysis of chemical composition (wt\%) in micro-areas for alloy after plastic processing, oxidation in air during $300 \mathrm{~h}$

In addition, after the oxidation of the alloy at $700{ }^{\circ} \mathrm{C}$ for 1000 and $2000 \mathrm{~h}$, along with the oxidation layer, partially descaled sites were observed (Figure 4). The cause of delamination of the scale may be stresses arising as a result of its build-up or thermal stresses (caused by the difference of thermal expansion coefficients of aluminum oxide and FeAl) occurring during cooling of the alloy from the oxidation temperature. This hypothesis is confirmed by the results of microanalysis of the chemical composition shown in Figure $\mathbf{5}$. They indicate that the oxide layer (area 2) contained mainly oxygen and aluminum and a small amount of chromium and iron, while area 1, on which the scale was exfoliated, had a chemical composition similar to the composition of the tested alloy. This means that the material did not have time to oxidize again and the detachment of the scale could have occurred as a result of heat stress during cooling. 

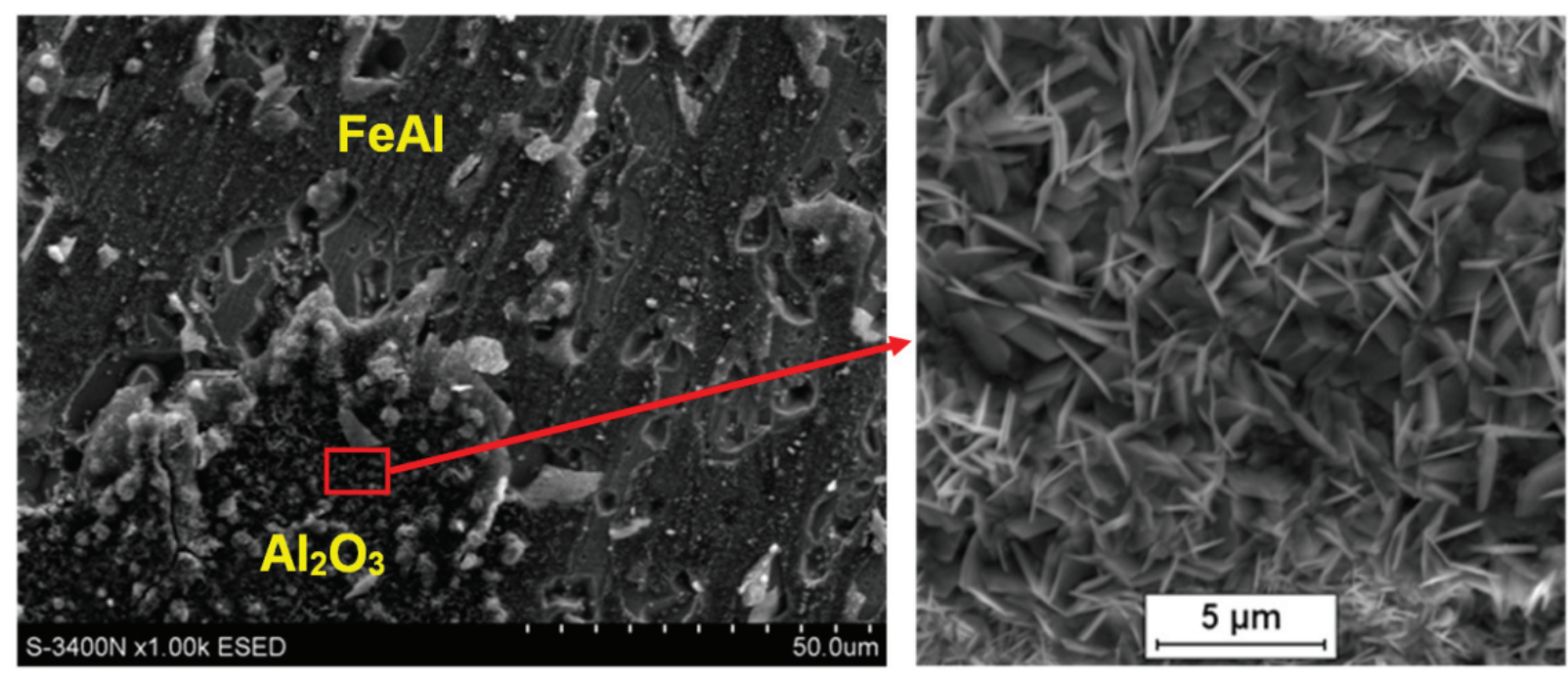

Figure 4 Morphology of $\mathrm{Al}_{2} \mathrm{O}_{3}$ oxides after oxidation for $1000 \mathrm{~h}$ in the environment of water vapor Fe40AI5Cr0.2TiB alloy after plastic processing
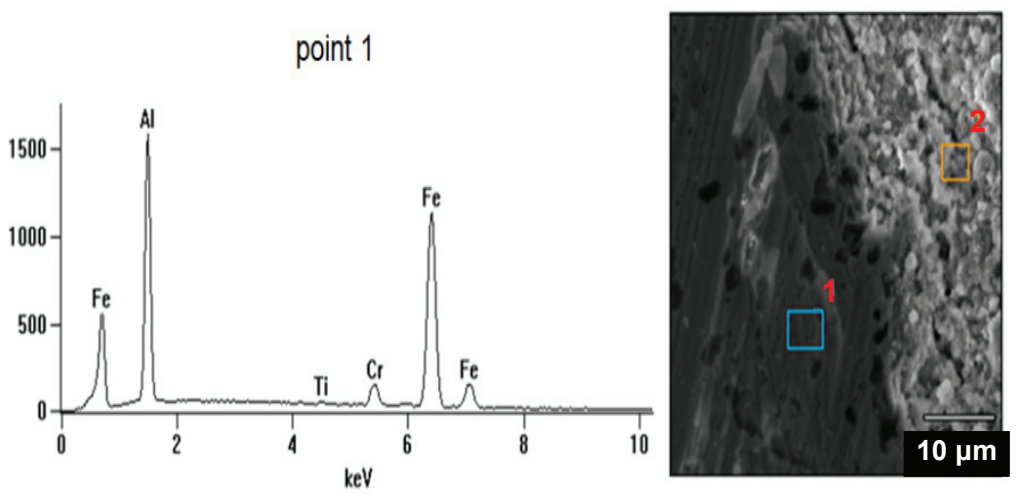

point 2

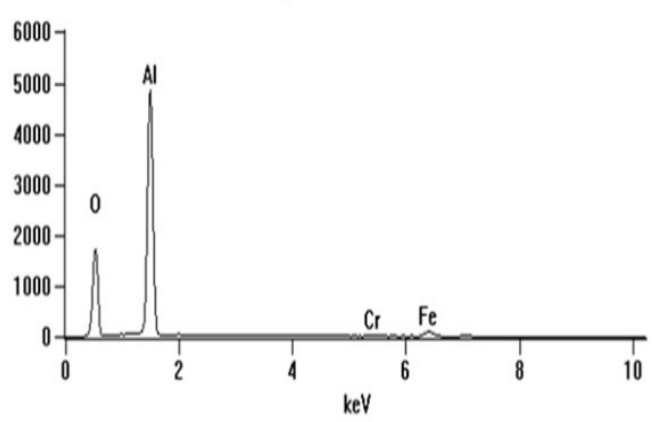

Figure $5 \mathrm{X}$-ray microanalysis of chemical composition in micro-areas for alloy after plastic processing, oxidation in water vapor during $1000 \mathrm{~h}$

\section{CONCLUSION}

The tests have shown that $\mathrm{Fe} 40 \mathrm{Al} 5 \mathrm{Cr} 0.2 \mathrm{TiB}$ alloy has a higher resistance to oxidation at $700{ }^{\circ} \mathrm{C}$ in the air environment than water vapor. It has also been shown that the material after crystallization has greater corrosion resistance at $700{ }^{\circ} \mathrm{C}$ in both air and water vapor environment. Corrosion products have morphologies of fine needles and are found on all samples tested in this work. The explanation of the differences between the course of Fe40Al5Cr0.2TiB alloy oxidation compared to classic engineering materials designed for high temperature operation requires further research.

\section{ACKNOWLEDGEMENTS}

The paper is financed from funds within the scope of work No. 11/990 / BK_19 / 0063

\section{REFERENCES}

[1] LIU, Feng-Xiao, HUANG, Bai-Un, ZHOU, Ke-Chao, LIU, Yong and CHEN, Jian-Xun. Present status and future prospects of FeAl alloy. Materials Science and Engineering of Powder Metallurgy. 2000, vol. 5, no. 3, pp $193-200$. (in Chinese) 
[2] SUN, Yang-Shan, YU, Xin-Guan, XUE, Feng, MEl, Jian-Ping, HUANG, Hai-Bo and WANG, Shi-Gin. Study of Fe 3 Albased intermetallics. Materials Review. 2000, vol. 11, no. 8, pp. 66-67. (in Chinese)

[3] BRUMM, M.W and GRABKE, Hans J. Oxidation behaviour of NiAl-II. Cavity formation beneath the oxide scale on nial of different stoichiometries. Corrosion Science. 1993. vol. 33, no. 4, pp.547-553.

[4] KUPKA, Marian, STĘPIEŃ, Karol. Hydrogen permeation in Fe-40 at\% Al alloy at different temperatures, Corrosion Science. 2009. vol. 5, pp. 699-702.

[5] KHOSHHAL Razieh. Investigation of oxidation behavior of synthesized $\mathrm{Fe}_{2} \mathrm{Al}_{5}$ and FeAl. Metal Powder Report D. January/February 2019. Vol.74, no 1 d.pp.30-34.

[6] MASSALSKI T. B. Binary alloy phase diagrams. ASM METALS PARK, OH, 1986, p. 112.

[7] DANNG NGOC CHAN, Christophe, HUVIER C. and DINHUT J.F. High temperature corrosion of some B2 iron aluminides. Intermetallics. 2001, vol. 9, pp. 817-826.

[8] DINGQIANG, Li, YUN, Xi and DONGLIANG Lin. Oxidation behavior of FeAl alloys with and without titanium. Journal of Materials Science. 2001. vol. 36, no. 4, pp. 979-983.

[9] RONG, Ju, WANG, Xiao, ZHANG, Yannan, FENG, Jing, ZHONG, Yi, YU, Xiaohua and ZHAN Zhaolin. $\mathrm{Al}_{2} \mathrm{O}_{3} / \mathrm{FeAl}$ interfacial behaviors by yttrium doping in high temperature oxidation. Ceramics International. 2019. https://doi.org/10.1016/j.ceramint.2019.07.253.

[10] ZHANG, Zhigang, GESMUNDO, F., HOU, P.Y. and NIU, Yuging. Criteria for the formation of protective $\mathrm{Al}_{2} \mathrm{O}_{3}$ scales on Fe-Al and Fe-Cr-Al alloys. Corrosion Science. 2006. vol. 48, pp. 741-765

[11] HUANG, Yuanding, YANG W.Y., CHEN G.L. and SUN Z.Q. On the effect of the B2 thermomechanical treatment in improving the room temperature ductility of Fe3Al-based alloys. Intermetallics. 2001. vol. 9, pp. 331.

[12] JÓŹWIAK, Stanisław, KARCZEWSKI, Krzysztof and BOJAR, Zbigniew. The effect of loading mode changes during the sintering process on the mechanical properties of FeAl intermetallic sinters. Intermetallics. 2013. vol. 33, pp. 99-104.

[13] CEBULSKI, Janusz and TYTKO, Kazimierz, Plastic processing by extrusion, in particular of alloys based on FeAI intermetallic phase. Patent No. 208310, decision of the Patent Office of the Republic of Poland of 2010. November 26.

[14] CEBULSKI Janusz. Heat resistance of alloys based on the FeAl intermetallic phase. Publisher of the Silesian University of Technology, Gliwice, 2014 (in Polisch)

[15] MROWEC, Stanisław, and WEBER Teodor. Metal gas corrosion, Publisher of the Silesia, Katowice, 1975 (in Polish)

[16] FORNALCZYK, Agnieszka, CEBULSKI, Janusz and PASEK, Dorota. The morphology of corrosion products in FeAl alloys after heat resistance tests at different temperatures. Solid State Phenomena. 2015, vol. 227, pp. 409412. 